Research Article

\title{
Effects of Low Volume Fraction of Polyvinyl Alcohol Fibers on the Mechanical Properties of Oil Palm Shell Lightweight Concrete
}

\author{
Ming Kun Yew, ${ }^{1}$ Hilmi Bin Mahmud, ${ }^{1}$ Bee Chin Ang, ${ }^{2}$ and Ming Chian Yew ${ }^{1}$ \\ ${ }^{1}$ Department of Civil Engineering, Faculty of Engineering, University of Malaya, Lembah Pantai, 50603 Kuala Lumpur, Malaysia \\ ${ }^{2}$ Center of Advanced Materials, Department of Mechanical Engineering, Faculty of Engineering, \\ University of Malaya, 50603 Kuala Lumpur, Malaysia
}

Correspondence should be addressed to Ming Kun Yew; davidyew1983@gmail.com

Received 9 August 2014; Revised 24 November 2014; Accepted 24 November 2014

Academic Editor: Hao Wang

Copyright @ 2015 Ming Kun Yew et al. This is an open access article distributed under the Creative Commons Attribution License, which permits unrestricted use, distribution, and reproduction in any medium, provided the original work is properly cited.

\begin{abstract}
This paper presents the effects of low volume fraction $\left(V_{f}\right)$ of polyvinyl alcohol (PVA) fibers on the mechanical properties of oil palm shell (OPS) high strength lightweight concrete mixtures. The slump, density, compressive strength, splitting tensile strength, flexural strength, and modulus of elasticity under various curing conditions have been measured and evaluated. The results indicate that an increase in PVA fibers decreases the workability of the concrete and decreases the density slightly. The 28-day compressive strength of oil palm shell fiber-reinforced concrete (OPSFRC) high strength lightweight concrete (HSLWC) subject to continuous moist curing was within the range of $43-49 \mathrm{MPa}$. The average modulus of elasticity $(E)$ value is found to be $16.1 \mathrm{GPa}$ for all mixes, which is higher than that reported in previous studies and is within the range of normal weight concrete. Hence, the findings of this study revealed that the PVA fibers can be used as an alternative material to enhance the properties of OPS HSLWC for building and construction applications.
\end{abstract}

\section{Introduction}

Concrete is the most widely used construction material in civil engineering projects worldwide. Huge quantities of different types of concrete have been produced annually. From the various kinds of concrete, lightweight concrete (LWC) is one of the most interesting subjects for researchers. LWC is used extensively by the building construction industry as nonstructural wall panels, partitions, light tiles, bricks, and architectural exterior finishing. Since their mechanical properties are considerably lower than those for normal weight concrete, the structural use of LWC is limited as load-bearing structural members. In order to use LWC for structural purposes, the material must be engineered to provide adequate strength, ductility, or a combination of both. Hence, the amount of lightweight aggregate concrete (LWAC) is increasing, and research and development are ongoing worldwide to develop new techniques and materials as well as investigating the engineering properties of such materials. Recently, a high strength lightweight aggregate concrete (HSLWAC) achieved a compressive strength in the range of 40-100 MPa by using several types of LWAs [1-4]. However, an increase in concrete strength results in brittleness of the concrete during compression and tension [5-7], specifically in the case of LWAC [6]. By advancement in fiber-reinforced cementitious composites, lightweight cement composites reinforced with a small amount of discontinuous (steel, polypropylene, and nylon) fibers may prove themselves as favourable construction materials. However, the main disadvantage of adding steel fibers into OPSLWC in a fresh state is its significant reduction in slump value and increased density [8]. Chen and Liu [7] have intensively studied the effect by using $1 \%$ of volume content of polypropylene fibers (length: $15 \mathrm{~mm}$, aspect ratio: 150) on LWC. Based on their findings, the addition of polypropylene fibers into LWC mixtures using expanded clay resulted in a reduction of slump values of 
about $20.8 \%$. Furthermore, the addition of polypropylene and nylon insignificantly increased the mechanical properties of OPS concrete, particularly for the tensile strength [9]. A new method that can be adopted to resolve the brittle texture of LWAC is to combine the PVA fibers with heat-treated OPS concrete to enhance its mechanical properties.

The most popular method of LWC production is through the use of LWAs [10], which may be either natural or manufactured. The LWA can be natural aggregates such as pumice, scoria, and those of volcanic origin whereas artificial aggregates include expanded blast-furnace slag, vermiculite, and clinker aggregates [11]. Another type of natural LWA is agricultural resource OPS. It has known that there are large amounts of agricultural residue in countries where the oil palm industry is dominant such as Malaysia, Indonesia, and Nigeria. Malaysia is one of the world leaders in the production and export of palm oil [12]. The production of OPS has estimated that over 4 million tonnes are produced annually in this country alone [13]. The densities of OPS are within the range of most typical structural LWAs [14-16]. Structural LWC is typically defined as concrete with an oven-dry density less than $2000 \mathrm{~kg} / \mathrm{m}^{3}[17,18]$. The 28 -day oven-dry density for the crushed OPS mixes range between $1871-1876 \mathrm{~kg} / \mathrm{m}^{3}$ [4]. It has reported that the mechanical properties of OPS concrete are lower than other types of LWAC [10]. Recently, Yew et al. [4] reported that the different species and age categories of OPS coarse aggregates show the most significant impact on the performance of HSLWC compared to previous studies.

Most of the research on OPS lightweight concrete has focused on the investigation of their engineering properties as there is inadequate information concerning the enhancement of its low mechanical properties. Despite there have many advantages of incorporating steel fibers into OPS LWC. However, steel fibers pose several drawbacks; in particular, the workability of fresh concrete is reduced, and the dead load of the composite is increased [8]. To the authors' knowledge, no studies have been conducted regarding the properties of OPS concrete that incorporate PVA fibers. Therefore, this study focuses on investigating the effects of various low $V_{f}$ of polyvinyl alcohol (PVA) fibers on the mechanical properties of LWAC subject to different curing conditions.

\section{Materials and Methods}

\subsection{Materials}

2.1.1. Cement. The cement used in this study is ASTM type I ordinary Portland cement (OPC) [19] with a specific gravity of $3.14 \mathrm{~g} / \mathrm{cm}^{3}$. The Blaine's specific surface area for this cement is $3510 \mathrm{~cm}^{2} / \mathrm{g}$. The chemical compositions and physical properties of OPC are tabulated in Table 1.

2.1.2. Water and Superplasticizer (SP). Potable water is used for all mixes. The SP used in this study is polycarboxylic ether (PCE) supplied by BASF, which complies with ASTM C494/C494 M-13. The amount of SP for all mixes is kept constant, with a value $1.5 \%$ of cement weight in order to facilitate workability of the concrete.
TABLE 1: Chemical composition and physical properties of OPC.

\begin{tabular}{lc}
\hline Chemical composition (\%) & \\
$\mathrm{SiO}_{2}$ & 21.28 \\
$\mathrm{Fe}_{2} \mathrm{O}_{3}$ & 3.36 \\
$\mathrm{CaO}$ & 64.64 \\
$\mathrm{MgO}$ & 2.06 \\
$\mathrm{Al}_{2} \mathrm{O}_{3}$ & 5.60 \\
$\mathrm{SO}_{3}$ & 2.14 \\
$\mathrm{Physical} \mathrm{properties}$ & \\
LOI & 0.64 \\
Specific gravity & 3.14 \\
Blain specific surface area $\left(\mathrm{cm}^{2} / \mathrm{g}\right)$ & 3510 \\
\hline
\end{tabular}

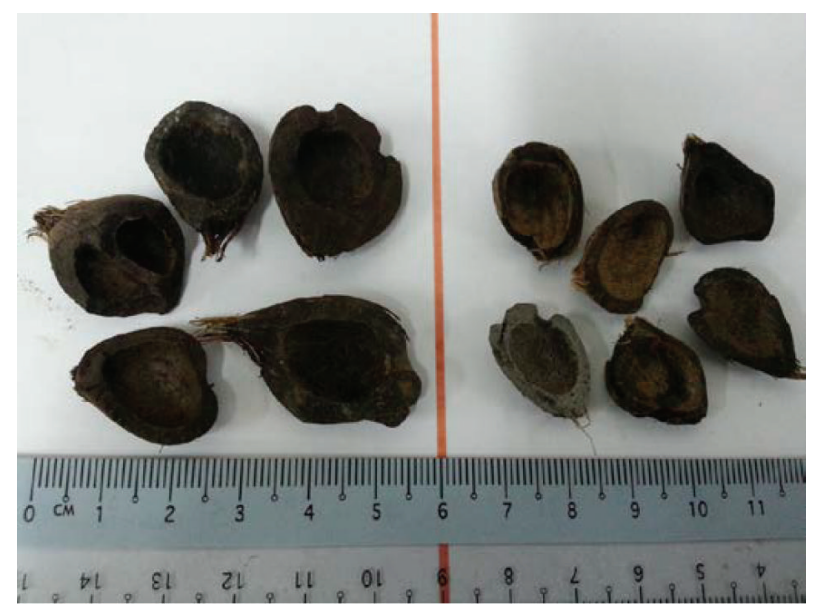

(a)

(b)

Figure 1: Original dura (a) and tenera (b) OPS aggregates.

2.1.3. Aggregates. Local mining sand is used as fine aggregates, having a specific gravity, fineness modulus, water absorption, and maximum grain size of $2.67 \mathrm{~g} / \mathrm{cm}^{3}, 2.71$, $0.95 \%$, and $4.75 \mathrm{~mm}$, respectively.

Figure 1 shows the different species of original dura and tenera OPS waste from a local crude palm oil producing mill. In this study, the OPS aggregates used are dura species. The original dura OPS was washed and sieved using a $12.5 \mathrm{~mm}$ sieve. The OPS aggregates retained in the sieve were collected and then crushed using a stone-crushing machine in the laboratory as shown in Figure 2. The crushed OPS aggregates were sieved using a $9.5 \mathrm{~mm}$ sieve to remove OPS aggregates with sizes greater than $9.5 \mathrm{~mm}$ (Figure 3). It has ben reported that the maximum size of OPS changes from original $(12.5 \mathrm{~mm})$ to crushed $(9.5 \mathrm{~mm})$. The broken edges of dura OPS are rough and spiky improved the physical bond between the aggregates and hydrated cement paste and yields higher compressive strength [4]. Furthermore, the OPS aggregates were heat treated at $60^{\circ} \mathrm{C}$ over a period of $0.5 \mathrm{~h}$ using a temperature-controlled laboratory oven. Once cooled to room temperature, they were weighed under dry room conditions and immersed in water for $24 \mathrm{~h}$. Yew et al. [20] found that OPS aggregates were subjected to heat treatment at 


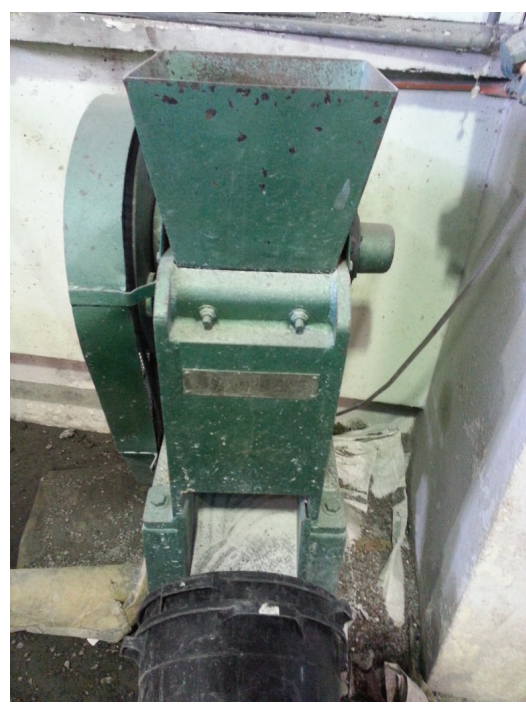

FIGURE 2: Stone-crushing machine for OPS aggregates.

this temperature setting and duration of the period improved the performance of OPS properties without compromising the strength of the OPSC. Due to the high water absorption of OPS, it was subsequently air dried in the laboratory to attain a saturated surface dry (SSD) condition before mixing. The difference in quality of the crushed OPS surface between heat treatment and without heat treatment condition was reported by Yew et al. [20] and shown in Figure 4. The physical properties of the OPS used are shown in Table 2.

2.1.4. Fibers. A photograph of the polyvinyl alcohol (PVA) fibers is shown in Figure 5 and their physical properties are listed in Table 3.

2.2. Mix Proportions. The mix proportions used in this study have been shown in Table 4. The amount of volume fraction $\left(V_{f}\right)$ of fibers added to the concrete mix typically ranges between 0.1 and $3.0 \%$ [21]. However, fibers with an extremely high $V_{f}$ tend to "ball" in the mix and create workability problems. Hence, a low volume fraction $(\leq 0.5 \%)$ for the PVA fibers is used in this study. The volume fractions of PVA fibers in the OPS concrete are $0,0.125,0.25,0.375$, and $0.5 \%$. The dosages of water and superplasticizer are kept constant for all mixes.

2.3. Test Methods and Curing Regimes. The procedure adopted for mixing the fiber-reinforced concrete involves the following steps. The sand and OPS are first poured into a concrete mixer and dry mixed for $1 \mathrm{~min}$. Following this, the cement is spread and dry mixed for $1 \mathrm{~min}$, after which the specified amount of fibers is distributed and mixed for $3 \mathrm{~min}$ in the mix. This is followed by the addition of water and superplasticizer with a mixing time of $5 \mathrm{~min}$. Slump test is carried out on the mixture prior to sample casting. The concrete specimens are cast onto oiled moulds and a poker vibrator is used to eliminate the amount of air bubbles in the mix. For each mixture, 18 cubes $(100 \times 100 \times 100 \mathrm{~mm})$
TABLE 2: Physical properties of crushed-heat treatment dura OPS aggregates.

\begin{tabular}{lcc}
\hline Physical property & OPS & OPS $^{*}$ \\
\hline Maximum size $(\mathrm{mm})$ & 9.5 & 9.5 \\
Specific gravity (saturated surface dry) & 1.35 & 1.31 \\
Compacted bulk density $\left(\mathrm{kg} / \mathrm{m}^{3}\right)$ & 632 & 628 \\
Water absorption $(24 \mathrm{~h})(\%)$ & 23.8 & 21.0 \\
Aggregate impact value $(\%)$ & 2.38 & 2.36 \\
\hline
\end{tabular}

${ }^{*}$ Dried OPS.

TABLE 3: Physical properties of polyvinyl alcohol fibers.

\begin{tabular}{lc}
\hline Parameter & Polyvinyl alcohol \\
\hline Length & $30 \mathrm{~mm}$ \\
Filament diameter & 660 microns \\
Specific gravity & 1.3 \\
Tensile strength & $800 \mathrm{MPa}$ \\
Flexural strength & $23 \mathrm{GPa}$ \\
Melting point & $225^{\circ} \mathrm{C}$ \\
Colour & Yellow \\
Water absorption & $<1 \%$ by weight \\
Alkali resistance & Excellent \\
\hline
\end{tabular}

TABLE 4: Mix proportions $\left(\mathrm{kg} / \mathrm{m}^{3}\right)$.

\begin{tabular}{lccccc}
\hline Mix code & Cement & Water & Sand & OPS & $\begin{array}{c}\text { Fiber volume } \\
(\%)\end{array}$ \\
\hline V0 & 530 & 155 & 920 & 340 & 0 \\
V0.125 & 530 & 155 & 920 & 340 & 0.125 \\
V0.250 & 530 & 155 & 920 & 340 & 0.250 \\
V0.375 & 530 & 155 & 920 & 340 & 0.375 \\
V0.500 & 530 & 155 & 920 & 340 & 0.500 \\
\hline
\end{tabular}

are used to determine the compressive strength at $1,3,7,28$, and 90 days. In addition, two cylinders (diameter: $150 \mathrm{~mm}$, height: $300 \mathrm{~mm}$ ), three cylinders (diameter: $100 \mathrm{~mm}$, height: $200 \mathrm{~mm})$, and three prisms $(100 \mathrm{~mm} \times 100 \mathrm{~mm} \times 500 \mathrm{~mm})$ are used to determine the modulus of elasticity, indirect tensile strength, and flexural strength, respectively, on the 28th day. The specimens are demoulded approximately 24 hours after casting.

The specimens are cured under three types of curing conditions in order to determine the effects of curing environment on the 28-day compressive strength of OPS concrete, as listed below.

CC: the specimens are cured in water at $23 \pm 3^{\circ} \mathrm{C}$ until the time of testing.

14C: the specimens are cured in water for 13 days after demoulding and then being air-cured in laboratory environment with a relative humidity $(\mathrm{RH} \%)$ of $60 \pm 15$ and a temperature of $28 \pm 3^{\circ} \mathrm{C}$. 


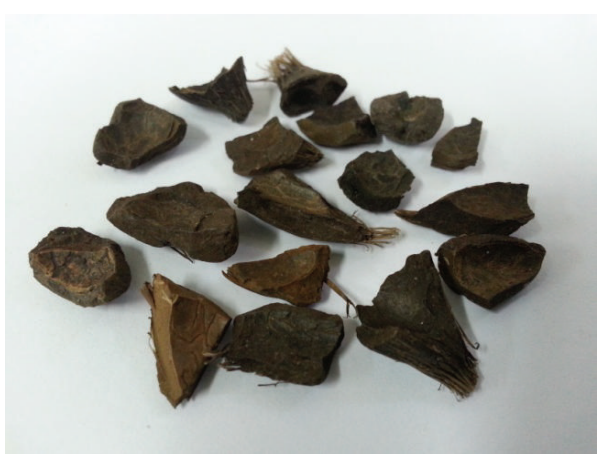

(a)

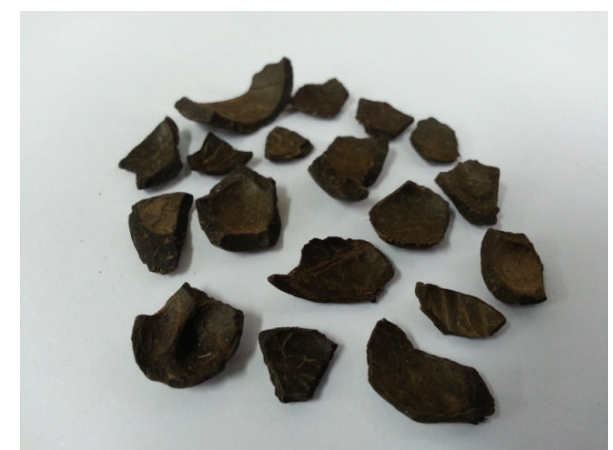

(b)

Figure 3: Crushed dura (a) and tenera (b) OPS coarse aggregates.

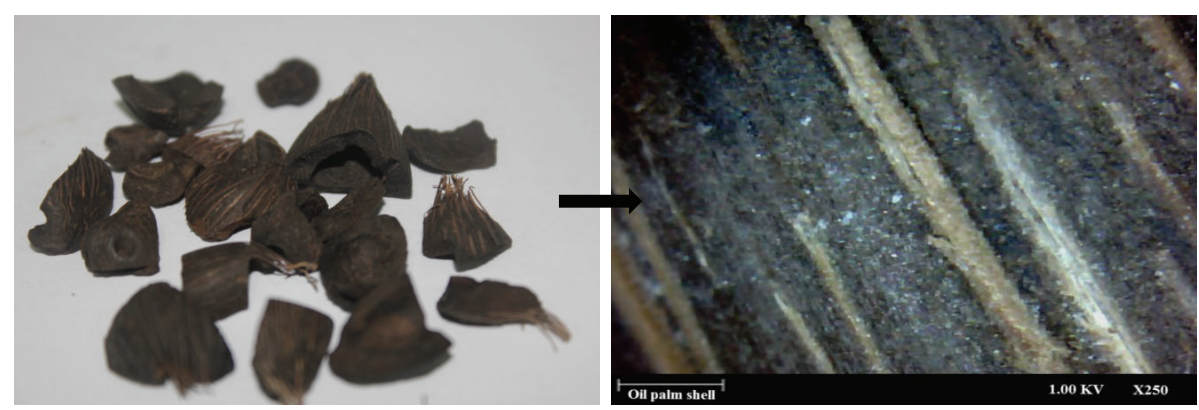

(a)

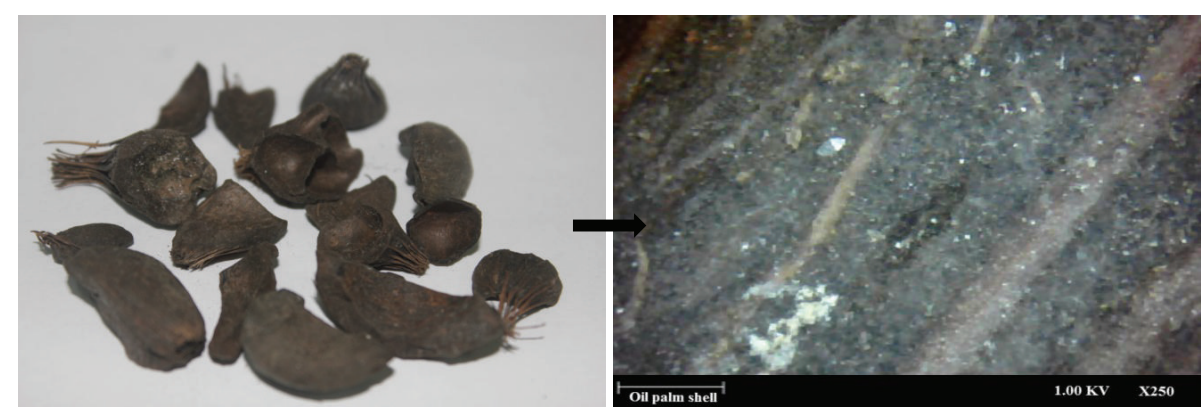

(b)

FIGURE 4: Images (left) and microscopic images (right) of crushed OPS aggregates: (a) with heat treatment and (b) without heat treatment.

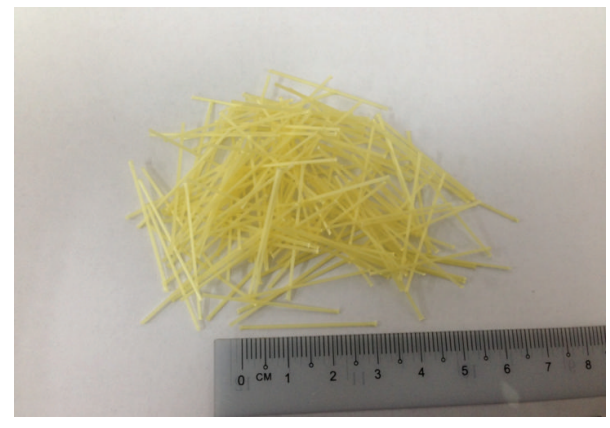

FIGURE 5: Photograph of polyvinyl alcohol fibers.

AC: the specimens are stored under laboratory environment after demoulding.

\section{Results and Discussion}

3.1. Workability and Slump of Fiber-Reinforced Concrete. Slump tests are carried out to determine the consistency of fresh concrete. The use of fibers is well known to influence the workability and flow ability of plain concrete intrinsically $[21,22]$. The slump of fresh OPS concrete decreases due to an increase in volume fraction of the PVA fibers. The quantity of water and SP is kept constant for all mixes in this study. The addition of fibers into the mixtures from 0 to $0.125,0.25$, 0.375 , and $0.5 \%$ decreases the workability by $5.0,7.5,22.5$, and $40.0 \%$, respectively. Noushini et al. [23] reported that the addition of monofilament PVA fibers into the mixtures from 0 to $0.5 \%$ reduced the slump at about $20 \%$. Figure 6 shows that there is a linear relationship between the PVA fiber volume fraction and slump for OPS concrete. 


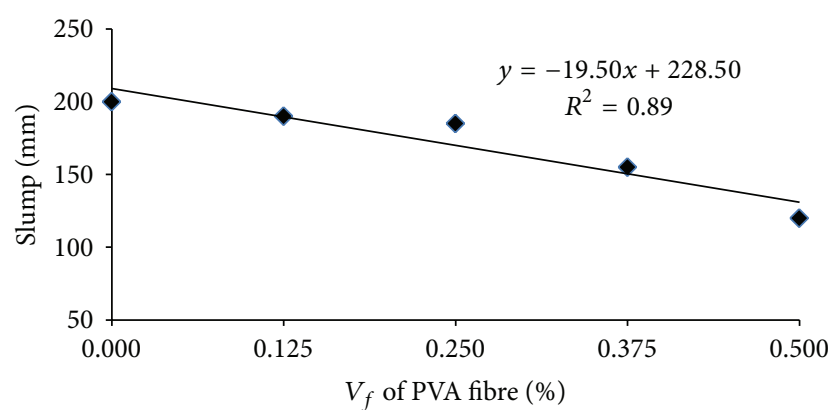

Figure 6: Relationship between PVA fiber volume fraction and slump.

The declining trend in slump value is attributed to the fact that the addition of fibers creates a network structure in the concrete, which restraints the mixture from segregation and flow. It can be ascertained that the fibers will absorb more of the cement paste in order to "wrap around." This phenomenon is due to the high content and large surface area of the fibers, and an increase in viscosity of the mixture promotes a decrease in slump [24]. However, a number of studies have attempted to overcome the segregation problem by adding superplasticizers and using optimum proportions of aggregates and sand into the concrete mixtures to achieve high workability and flow ability [25-28]. Campione et al. [29] reported that good workability has been achieved for pumice and expanded clay LWAC reinforced with steel fibers by adding $1.5 \%$ superplasticizer of the cement weight. In general, the use of a low dosage of fibers is recommended to ensure good workability for fiber-reinforced concrete [30].

3.2. Hardened Density. Steel fibers are the most commonly used fibers for improving the mechanical properties of LWAC amongst the various types of fibers [31]. The relationship between steel fiber volume fraction and density of Shafigh et al. [8] shows that the density increases with an increase in fiber volume fraction. However, the low specific gravity of PVA fibers provides a lower density fiber-reinforced LWC with higher strength.

Three types of densities, namely, demoulded density, 28day air-dry density, and oven-dry density, are measured for all mixes. The density of the concrete mixes decreases slightly with an increase in fiber volume fraction, which is attributed to the low specific gravity of the PVA fibers [32]. The 28-day air-dry density of the V0.5 mix is found to be approximately $1939 \mathrm{~kg} / \mathrm{m}^{3}$, which indicates that the density falls within the range of those for structural lightweight concrete even though the volume fraction of PVA fibers is only $0.5 \%$. The relationship between the demoulded, air-dry and oven-dry densities with respect to the volume fraction of PVA fibers is illustrated in Figure 7. The 28-days air-dry and oven-dry densities range from 1939 to $1970 \mathrm{~kg} / \mathrm{m}^{3}$ and 1914 to $1941 \mathrm{~kg} / \mathrm{m}^{3}$, respectively, for various volume fractions. It is found that increasing the volume fraction from 0 to 0.125 , $0.25,0.375$, and $0.5 \%$ decreases the demoulded density, air dry density, and oven-dry density slightly by $0.2,0.6,1.0$, and

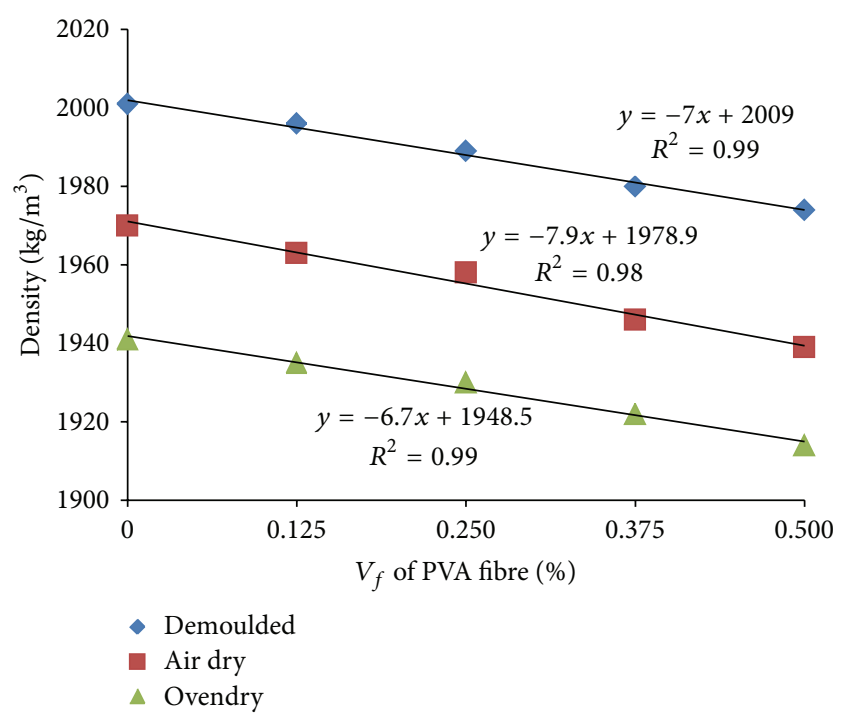

FIGURE 7: Relationship between PVA fiber volume fraction and densities.

$1.3 \%$ at 1 -day age, $0.4,0.6,1.2$, and $1.6 \%$ at 28 -days age and $0.3,0.6,1.0$, and $1.4 \%$ at 28 -days age, respectively. Although the addition of the very low specific gravity PVA into heattreated OPS concrete produced an insignificant change in density. However, their contribution to the density cannot be ignored. It might be attributed to PVA tend to displace mortar in concrete as the diameter of PVA is $0.66 \mathrm{~mm}$. Furthermore, it has been reported that there is a marginal reduction in density without alterations in mechanical properties when polypropylene (PP) fibers are added into OPSFRC $[9,33]$. Hence, there is substantial cost savings by providing less dead load for LWC in this study.

\subsection{Compressive Strength}

3.3.1. Continuous Moist Curing. The effects of PP fibers $(L=$ $15 \mathrm{~mm}$ and $D=0.10 \mathrm{~mm}$ ) on the properties of LWAC have been much researched amongst the various types of fibers. It has been reported that PP fibers result in a decrease in compressive strength of LWAC [24]. It can be seen that the compressive strength of concrete increases for all ages with an increase in PVA fiber volume fraction (Table 5). Increasing the PVA fiber volume fraction from 0 to $0.125,0.25,0.375$, and $0.50 \%$ increases the compressive strength by roughly $0.9,6.2$, 8.7, and $13.1 \%$ at 28 -days age and $0.6,8.0,10.0$, and $18.9 \%$ at 90 days age, respectively. Comparison between the compressive strength of the fiber-reinforced concrete during the former and latter ages indicates that the rate of compressive strength development increases from the former to latter ages and is particularly more pronounced for concrete mixes with higher PVA fiber content. This trend can be clearly observed from the percentages of the 28-day compressive strength (shown within the parentheses) for each age in Table 5. It can be seen that the percentage of compressive strength at 3 days and 7 days decreases with an increase in PVA fiber volume fraction whereas the value increases at 90-day age. This trend is attributed to the higher rate of compressive strength gained at 
TABLE 5: Development of compressive strength of lightweight OPS FRC under continuous moist curing.

\begin{tabular}{|c|c|c|c|c|c|}
\hline \multirow{2}{*}{ Mix code } & \multicolumn{5}{|c|}{ Compressive strength $(\mathrm{MPa})^{\mathrm{a}}$} \\
\hline & $1 \mathrm{~d}$ & $3 \mathrm{~d}$ & $7 \mathrm{~d}$ & $28 \mathrm{~d}$ & $90 \mathrm{~d}$ \\
\hline \multirow{2}{*}{ V0 } & $29.32(68 \%)$ & $33.04(77 \%)$ & $39.48(92 \%)$ & 42.89 & $43.29(101 \%)$ \\
\hline & $(0.61)$ & $(0.33)$ & $(0.48)$ & $(0.49)$ & $(0.67)$ \\
\hline \multirow{2}{*}{ V0.125 } & $28.81(67 \%)$ & $32.61(75 \%)$ & $39.70(91 \%)$ & 43.29 & $43.54(101 \%)$ \\
\hline & $(0.83)$ & $(0.97)$ & $(0.62)$ & $(0.73)$ & $(0.89)$ \\
\hline \multirow{2}{*}{ V0.250 } & $28.95(64 \%)$ & $34.60(76 \%)$ & $39.92(88 \%)$ & 45.56 & $46.77(103 \%)$ \\
\hline & $(0.90)$ & $(0.97)$ & $(0.81)$ & $(0.86)$ & $(0.78)$ \\
\hline \multirow{2}{*}{ V0.375 } & $29.65(64 \%)$ & $35.88(77 \%)$ & $41.95(90 \%)$ & 46.62 & $47.60(102 \%)$ \\
\hline & $(0.83)$ & $(0.95)$ & $(0.75)$ & $(0.87)$ & $(0.95)$ \\
\hline \multirow{2}{*}{ V0.500 } & $30.66(63 \%)$ & $37.58(77 \%)$ & $43.75(90 \%)$ & 48.51 & $51.48(106 \%)$ \\
\hline & $(0.88)$ & $(0.80)$ & $(0.81)$ & $(1.22)$ & $(0.66)$ \\
\hline
\end{tabular}

${ }^{\mathrm{a}}$ The data in parentheses are percentages of 28-day compressive strength.

Note: the standard deviations (in MPa) of the corresponding mechanical properties are shown in the bracket (below).

latter ages, and the rate is particularly significant for the $0.5 \%$ PVA fiber volume fraction. The relative strength between the control and PVA fiber volume fraction from 0 to $0.125,0.25$, 0.375 , and $0.50 \%$ increases the compressive strength at about $0.9,0.6,2.7,2.1$, and $6.1 \%$ at 90 -day age as compared to 28 -day age. It is apparent that PVA fiber volume fraction up to $0.25 \%$, the performance of PVA fibers in the OPS concrete increases at latter ages, which is possibly due to the improvement of PVA fiber-mortar interfaces [34].

Shafigh et al. [8] have shown the possibility of producing grade 40 strength OPS concrete at the age of 28 days. Based on the findings of this study, it can be deduced that the production of grade 40 OPS concrete with lower cement content is possible [35], even with a low volume fraction of PVA fibers, relative to previous studies. In practical applications of concrete, the early-age compressive strength test can be used in replacement of the 28 days or other latter ages for the purpose of routine quality control. In this study, two equations are generated to predict the performance of the concrete in latter ages. By using new (1) at the early age compressive strength test, changes in concrete properties can be detected at an early stage and the appropriate corrective actions can be taken to improve concrete quality [36]:

$$
\begin{aligned}
& F_{28}=1.35 F_{7}-9.94, \\
& F_{90}=1.40 F_{28}-16.9 .
\end{aligned}
$$

3.3.2. Effect of Curing Condition. Figure 8 illustrates the 28days compressive strength of specimens subject to three curing conditions, namely, continuous curing (CC), 14days moist curing (14C) and no curing in the laboratory environment $(\mathrm{AC})$. It can be seen that the order of strength for the concrete is $\mathrm{CC}>14 \mathrm{C}>\mathrm{AC}$. The loss in 28 -day compressive strength of the specimens consisting of $0,0.125,0.25,0.375$, and $0.5 \%$ PVA fiber volume fraction is 14.9, 14.7, 13.7, 10.8, and $9.6 \%$, respectively, under AC curing. The values decrease to $5.4,6.4,6.8,8.3$, and $5.4 \%$, respectively, when the specimens are cured over a short period (14C).

The results show that the behaviour of OPS concrete containing PVA fibers up to $0.5 \%$ by volume under nocuring

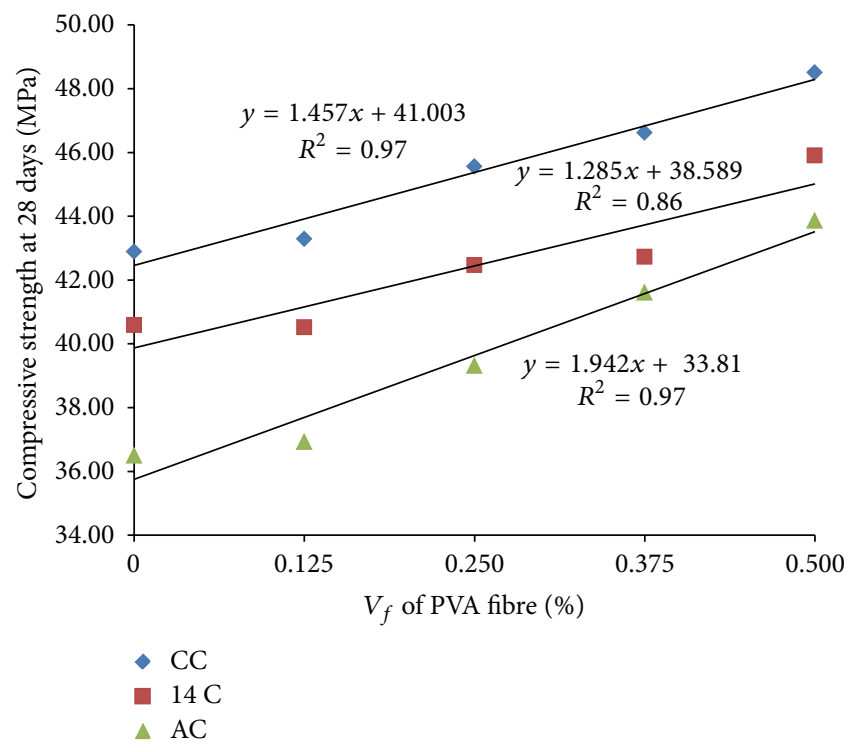

FIGURE 8: Relationship between PVA fiber volume fraction and compressive strength under different curing conditions on the 28 th day.

regimes is almost similar to that of OPS concrete under CC condition. However, OPS concrete with a PVA fiber volume fraction exceeding $0.375 \%$ exhibits lower strength loss under AC curing as compared to CC and 14C. This observation shows that although the strength of OPS concrete appears to be sensitive to poor curing [8], the sensitivity of compressive strength loss decreases by incorporating PVA fibers with a volume fraction exceeding $0.375 \%$. This is due to the possibility that when the PVA fiber content is high (particularly a volume fraction of $0.5 \%$ ), the fibers arrest the development and number of original shrinkage cracks. Therefore, it can be deduced PVA fibers offer an additional benefit, whereby the sensitivity of OPS concrete is reduced under poor curing environments. Furthermore, it can be observed from Figure 7 that the 28-day compressive strength of OPS concrete increases linearly with an increase in PVA 


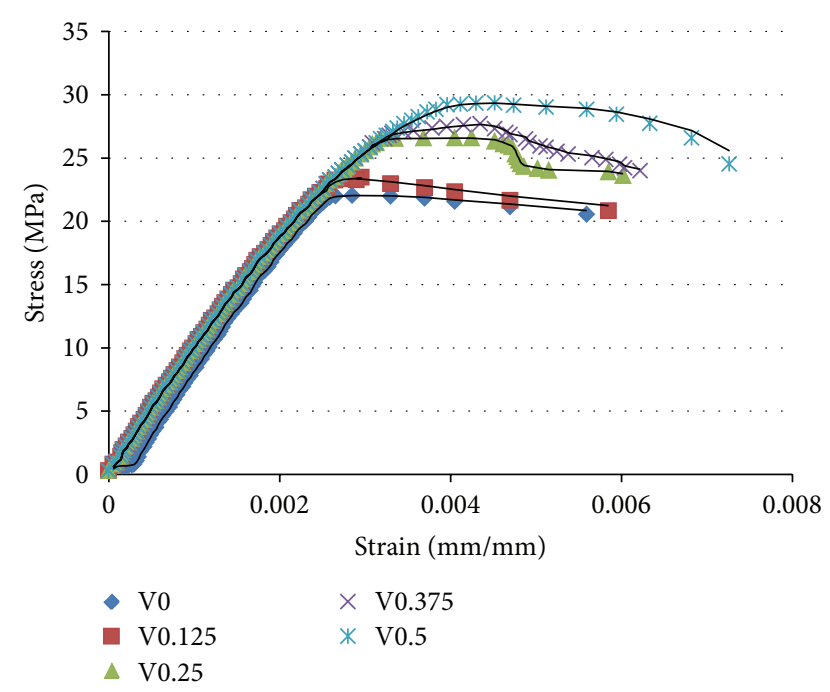

FIGURE 9: Typical stress-strain relationship.

fibers volume fraction. A prominent feature of this figure is that the slope of the straight line for AC specimens is the steepest (slope $=1.942$ ), whereas the slope for CC and $14 \mathrm{C}$ specimens is nearly equal with a value of 1.457 and 1.285 , respectively. This shows the positive effect of incorporating PVA fibers into OPS concrete even in poor curing conditions.

3.3.3. Strain at Peak Stress. Figure 9 shows the stress-strain curves of sample at 28-day continuously moist curing for V0, V0.125, V0.25, V0.375, and V0.5 mixes under compression. The stress-strain curves of most LWACs for both normal and high strength levels are typically linear to levels approaching $90 \%$ or higher of the failure strength $[31,37,38]$. It is usually 30 to $45 \%$ for a normal weight concrete (NWC) [31]. This shows that LWACs are more brittle than NWCs, which causes its explosive fracture after peak load [39]. One of the disadvantages that prevented its use in concrete structures is due to the brittle nature of LWC. Therefore, the possible solution is to use PVA fibers to enhance the brittleness of LWC.

From the results, the strain at peak stress $(\varepsilon)$ of the V0, V0.125, V0.25, V0.375, and V0.5 mixes measured in this study varies from 0.0029 to 0.0045 . The $\varepsilon$ value of the $\mathrm{V} 0$ and V0.125 mixes is of similar value of approximately 0.0030 . However, when the inclusion of PVA fiber is up to $0.25-$ $0.5 \%$, the $\varepsilon$ value increased about 41,52 , and $55 \%$, which is significant. It could be noted that the PVA fiber up to $0.25 \%$ reinforced OPSLWA shows different behavior to plain OPSC. This phenomenon might be attributed to arresting of cracks by PVA fibers which contribute to very large deformations before total uncontrollable collapse. It has been shown that, in contrast to many types of structural lightweight aggregate concretes, plain OPS concrete is a ductile material [40]. In addition, it was found that the addition of steel fiber into OPS concrete increases the strain capacity and improves its ductility performance [8]. However, the main disadvantage of adding steel fibers into OPSLWC is its significant increment in density compared with PVA fibers. Such improvement in the ductility performance of OPS concrete can be observed in
OPS concrete containing PVA. It is clear that by adding PVA to the OPS concrete the strain of the concrete corresponding to the peak stress increases significantly. Increasing in the strain capacity of concrete results in an increase in the area of the stress-strain diagram and energy absorption capacity and also changed the concrete into a more ductile material. The stress-strain relationship for uniaxial compression of OPSC and PVA fiber-reinforced OPSC is shown in Figure 9. It has been reported that the improvement in resistance to cracking due to restrained shrinkage is of the advantages of greater strain capacity of a concrete [41]. Furthermore, it should be noted that the $\varepsilon$ value of NWC with normal strength is in the range of 0.0015 to 0.002 [42]. Shafigh et al. had shown that when 0.5 and $1 \%$ volume fraction of the steel fiber is added to an OPS concrete, its $\varepsilon$ value increases about 20 and $35 \%$, respectively [8].

3.4. Splitting Tensile Strength. Fiber-reinforced concrete and polymer concrete have been developed over the years in order to improve the tensile strength of concrete [43]. It has been reported that the addition of fibers provides a significant increase in splitting tensile strength of LWAC and semiLWAC concrete [43-45]. Figure 10 shows the 28-day splitting tensile strength increases from 2.88 to $3.74 \mathrm{MPa}$ when the fiber content is increased from 0 to $0.5 \%$. The rate of increase for V0.125, V0.25, V0.375, and V0.5 mixes is determined to be $9.4,11.1,19.8$, and $29.9 \%$, respectively, which indicates a considerable improvement in the splitting tensile strength of the OPS concrete, even in the presence of low fiber content.

It has also been reported that the 28-days splitting tensile strength of OPS concrete under moist curing is within the range of $1.9-2.41 \mathrm{MPa}[46,47]$, which is approximately $6-10 \%$ of the corresponding cube compressive strength. Chen and Liu [24] investigated the effect of three types of fibers on the properties of expanded clay HSLWAC, in which the amount of each type of fibers is $1 \%$. They reported that PP fibers result in a slight reduction in splitting tensile strength of about $2 \%$. In this study, the splitting tensile strength for OPS concrete is determined to be $6.7 \%$, which falls within the range of $6.7-7.7 \%$, of the compressive strength. This shows that the PVA fibers obviously enhance the tensile to compressive strength ratio. Figure 10 shows the relationship between the splitting tensile strength and PVA fiber volume fraction. It is clear that the splitting tensile strength increases with an increase in PVA fiber content. The relationship between the two parameters is found to be parabolic, whereby $F_{t}=$ $(0.0171) V_{f}^{2}+(0.0991) V_{f}+2.798$ and the $R^{2}$ value is $0.97 . F_{t}$ and $V_{f}$ represent the splitting tensile strength $(\mathrm{MPa})$ and fiber volume fraction (\%), respectively. Furthermore, Figure 11 shows a parabolic correlation with a strong correlation $\left(R^{2}=\right.$ 0.97 ) between fiber volume (\%) and the splitting tensile strength to compressive strength.

An equation has been proposed to correlate splitting tensile strength of OPSFRC by Yap et al. [9] by incorporating $\mathrm{PP}$ and nylon fibers as shown in

$$
f_{t}=0.52 \sqrt{f_{\mathrm{cu}}}
$$




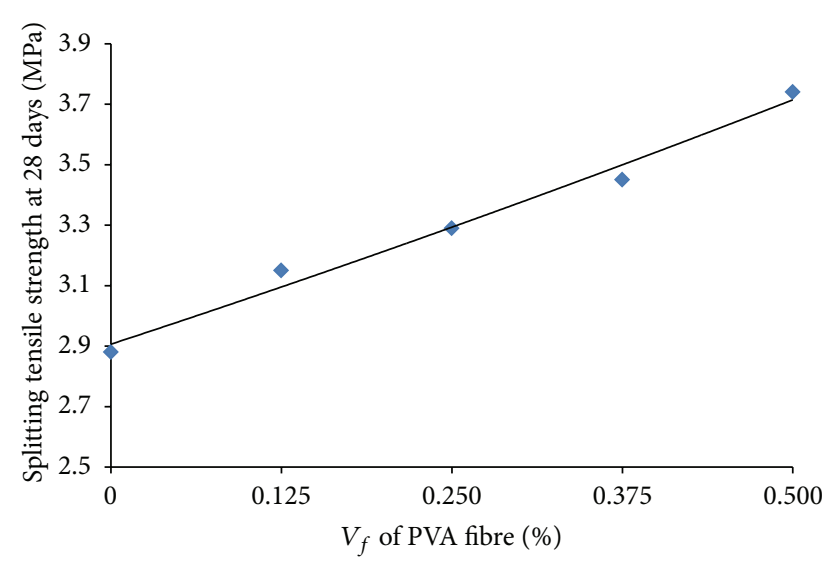

Figure 10: Relationship between PVA fiber volume fraction and splitting tensile strength.

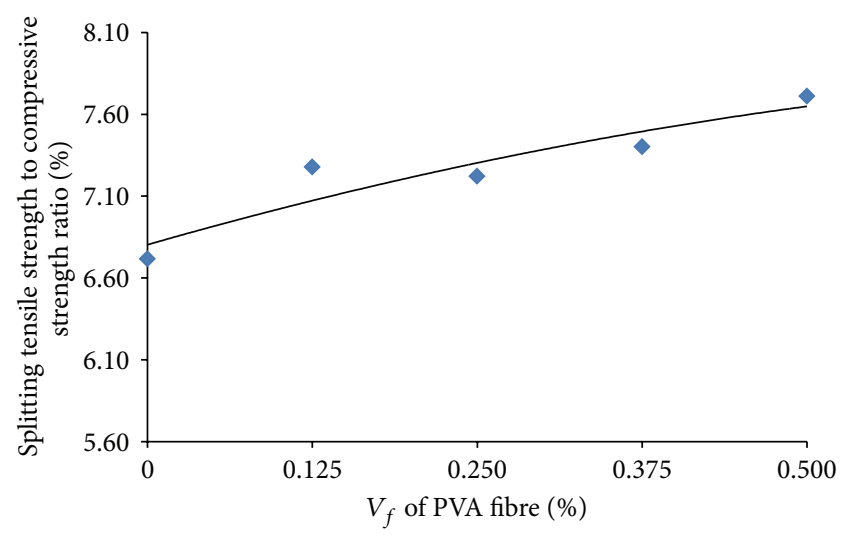

FIGURE 11: Relationship between PVA fiber volume fraction and the splitting tensile strength to compressive strength ratio.

where $f_{t}$ and $f_{\text {cu }}$ represent the splitting tensile and cube compressive strengths in $\mathrm{MPa}$, respectively.

A new equation to correlate splitting tensile strength and compressive strength of OPSFRC is proposed in (3), whereby a higher coefficient of correlation is produced (accuracy $= \pm 10 \%$ ). An accurate prediction of tensile strength of the concrete imperative in mitigating cracking problems minimizes the failure of concrete in tension and increases shear strength prediction as shown below

$$
f_{t}=0.49 \sqrt{f_{\mathrm{cu}}}
$$

3.5. Flexural Strength. The relationship between PVA volume fraction and flexural strength is shown in Figure 12. It can be seen that the 28-day flexural strength increases from 4.17 to $5.49 \mathrm{MPa}$, ranging from 9.7 to $11.3 \%$ of the 28 -day compressive strength when the fiber content is increased from 0 to $0.5 \%$. This range is higher than the findings of previous studies which focused on OPS LWAC $[46,48]$ and expanded clay LWA [49].

In comparison to mix V0, the rate of increase of flexural strength is obtained to be $9,26,28$, and $32 \%$ for V0.125, V0.25, V0.375, and V0.5 mixes, respectively. These rates indicate that

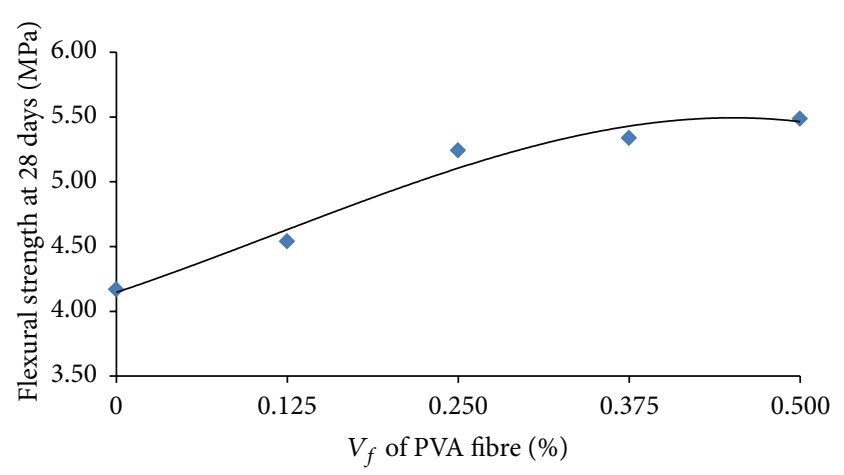

FIgURE 12: Relationship between PVA fiber volume fraction and flexural strength.

an increase in the PVA fiber volume fraction up to $0.25 \%$ exhibits a nearly similar effect on the increase in flexural strength (Figure 12). This phenomenon might be attributed to fiber clogging within the $0.25 \%$ volume fraction which causes more pores resulting in the similar effect on the increase in flexural strength. However, a significant increase in flexural strength is attained with a higher fiber volume fraction of $0.5 \%$ as compared to OPS concrete. Shi et al. [50] discovered that the addition of a small amount of fibers does not influence the flexural strength of lightweight concrete; however, the ductility is significantly improved. They believed that this may be due to the lower tensile strength of PP fibers as well as the weaker bonds between PP fibers and the cement matrix compared to PVA fibers.

A relationship between the flexural strength and cube compressive strength for OPS concrete has been proposed by Alengaram et al. [46], as given by the following equation:

$$
f_{r}=0.3 \sqrt[3]{f_{\mathrm{cu}}^{2}}
$$

Lo et al. [49] proposed the following equation for LWAC made with expanded clay aggregates:

$$
f_{r}=0.69 \sqrt{f_{\mathrm{cu}}}
$$

Furthermore, the equation for LWAC made with a combination of expanded shale and clay aggregate, for cube strengths, ranging from 20 to $60 \mathrm{MPa}$ [51] is follows:

$$
f_{r}=0.46 \sqrt[3]{f_{\mathrm{cu}}^{2}}
$$

A new equation has also been proposed to correlate flexural strength to compressive strength of OPSLWAC in this study. Equation (7) is suggested for OPSFRC with different volume fraction of PVA fibers to predict the flexural strength within $\pm 14 \%$ :

$$
f_{r}=0.39 \sqrt[3]{f_{\mathrm{cu}}^{2}}
$$

where $f_{r}, f_{t}$, and $f_{\text {cu }}$ represent the flexural, splitting tensile, and cube compressive strength, respectively, with units in MPa. 
TABLE 6: Measured and estimated flexural strength.

\begin{tabular}{lcccccc}
\hline Mix code & $\begin{array}{c}\text { 28-day compressive } \\
\text { strength (MPa) }\end{array}$ & $\begin{array}{c}\text { Measured flexural } \\
\text { strength (MPa) }\end{array}$ & $\begin{array}{c}\text { Equation (5) by } \\
\text { Alengaram et al. } \\
{[46]}\end{array}$ & $\begin{array}{c}\text { Equation (6) by } \\
\text { Lo et al. [49] }\end{array}$ & $\begin{array}{c}\text { Equation (7) by } \\
\text { CEB/FIP [51] }\end{array}$ & $\begin{array}{c}\text { Equation (7) in } \\
\text { this study }\end{array}$ \\
\hline V0 & 42.89 & 4.17 & 3.47 & 4.33 & 5.32 & 5.78 \\
V0.125 & 43.29 & 4.54 & 3.61 & 4.46 & 5.54 & 5.56 \\
V0.250 & 45.56 & 5.24 & 3.63 & 4.47 & 5.81 & 5.97 \\
V0.375 & 46.62 & 5.34 & 3.79 & 4.62 & 5.05 \\
V0.500 & 48.51 & 5.49 & 3.79 & 4.63 & 5.82 & 5.19 \\
\hline
\end{tabular}

Table 6 shows the estimated flexural strength using the four (2)-(5) as given. From the estimated flexural strength values, it can be seen that (7) is generally acceptable to predict the flexural strength of OPS concrete. It can be deduced from the results that the flexural strength of OPS concrete with and without fibers is comparable to artificial LWA with expanded shale and clay aggregates.

3.6. Modulus of Elasticity. In this study, the value of static modulus of elasticity $(E)$ is $15.3,15.6,16.3,16.4$, and $16.9 \mathrm{GPa}$ for mixes $\mathrm{V} 0, \mathrm{~V} 0.125, \mathrm{~V} 0.25, \mathrm{~V} 0.375$, and $\mathrm{V} 0.5$, respectively. These values indicate that the addition of PVA to OPS concrete has a significant effect on the $(E)$ value. This phenomenon might be attributed to the heat treatment on OPS enhancing the dimensional stability and surface quality of OPS which improve the adhesion between the aggregate and the cement matrix. In addition, the MOE of OPSFRC was found to be dependent on the fiber volume. It might be due to the fact the addition of fibers contributed to crack bridging which enhances the MOE of OPSFRC. Yap et al. [9] reported that the combined effect of both silica fume and fibers (PP and nylon) enhanced the MOE of OPSFRC, even higher compared to OPSC with crushed OPS. However, in the present study, the combined effect of both heat-treated crushed dura OPS and PVA fibers reduced the strain induced under compression loadings and eventually improved the MOE of OPSFRC significantly compared to previous studies.

In a previous study, the $(E)$ value of OPS concrete with total cementitious materials (cement/fly ash/silica fume) is reported to be $11 \mathrm{GPa}$, whereas the compressive strength is approximately $38 \mathrm{MPa}[35]$. The $(E)$ value of mix $\mathrm{V} 0$ is roughly $39 \%$ higher than this value. The use of dura OPS with heat-treated and PVA fibers has a significant effect on the compressive strength due to the enhanced adhesion between the OPS and PVA fibers with the cement matrix. Hence, it can be deduced that it is possible to attain a higher average $(E)$ value of $16.1 \mathrm{GPa}$ for OPSFRC.

It has been reported by CEB/FIP that the $(E)$ value of structural lightweight concrete ranges between 10 and $24 \mathrm{GPa}$ [51]. Swamy and Lambert [52] reported $(E)$ values within the range of $15-22 \mathrm{GPa}$ for LWAC made with pulverized fuel ash (PFA) aggregates. Mehta and Monteiro [53] reported that the $(E)$ value is 10 and $14 \mathrm{GPa}$ for 20 and $40 \mathrm{MPa}$ compressive strength LWC containing expanded clay aggregates, respectively. For normal weight concrete, the $(E)$ values range from 14 to $41 \mathrm{GPa}$ [54]. Thus, it can be deduced that the $(E)$ value measured for the concrete in this study falls within the range of normal weight and artificial lightweight aggregate concrete.

\section{Conclusion}

Based on the experimental results of this study, it can be found that the addition of PVA fibers enhanced the mechanical properties of concrete. The workability of fiber-reinforced concrete decreases by increasing the volume fraction of PVA fibers. A maximum reduction of $40 \%$ has been determined for OPS concrete with $0.5 \%$ PVA fiber content. Furthermore, the addition of PVA fibers with low specific gravity to the OPS mixtures reduces the density of the concrete. However, PVA fibers that contribute to the marginal reduction in density cannot be ignored. The compressive strength of OPS concrete has increased for all ages with an increase in PVA fibers. The effect of PVA on compressive strength of lightweight concrete has been shown more prominent at latter ages due to better fiber/matrix interface adhesion. The 28-day compressive strength of PVA fiber-reinforced OPS concrete is found to be within $43-49 \mathrm{MPa}$. The addition of PVA fiber up to $0.375 \%$ had a positive effect on the compressive strength loss under no curing (AC) condition. Therefore, it can be deduced that PVA fibers can be used to reduce the sensitivity of OPS concrete in poor curing environments. The inclusion of PVA fiber to OPS concrete increases the strain capacity corresponding to peak stress, which causes OPS concrete to become more ductile. The addition of PVA fibers also enhances the splitting tensile and flexural strengths significantly up to 30 and $32 \%$, respectively, compared to the control concrete. The inclusion of PVA fibers into OPS concrete has a significant effect on the modulus of elasticity. The $(E)$ value measured in this study is $16.1 \mathrm{GPa}$, which is higher compared to previous studies. Hence, it can be concluded that PVA fiber-reinforced OPS LWC showed the possibility and accepted performance for potential application in producing green composite concrete structures.

\section{Conflict of Interests}

The authors declare that there is no conflict of interests regarding the publication of this paper. 


\section{Acknowledgment}

The authors wish to extend their greatest appreciation to the University of Malaya for providing the financial support for this work under the University of Malaya Research Grant (UMRG), Grant no. RP018/2012C.

\section{References}

[1] O. Kayali, M. N. Haque, and B. Zhu, "Some characteristics of high strength fiber reinforced lightweight aggregate concrete," Cement and Concrete Composites, vol. 25, no. 2, pp. 207-213, 2003.

[2] M. H. Zhang, L. Li, and P. Paramasivam, "Flexural toughness and impact resistance of steel-fibre-reinforced lightweight concrete," Magazine of Concrete Research, vol. 56, no. 5, pp. 251-262, 2004.

[3] H. Costa, E. Júlio, and J. Loureno, "New approach for shrinkage prediction of high-strength lightweight aggregate concrete," Construction and Building Materials, vol. 35, pp. 84-91, 2012.

[4] M. K. Yew, H. Mahmud, B. C. Ang, and M. C. Yew, "Effects of oil palm shell coarse aggregate species on high strength lightweight concrete," The Scientific World Journal, vol. 2014, Article ID 387647, 12 pages, 2014.

[5] V. C. Li, "Large volume, high-performance applications of fibers in civil engineering," Journal of Applied Polymer Science, vol. 83, no. 3, pp. 660-686, 2001.

[6] A. R. Khaloo and M. Sharifian, "Experimental investigation of low to high-strength steel fiber reinforced lightweight concrete under pure torsion," Asian Journal of Civil Engineering, vol. 6, no. 6, pp. 533-547, 2005.

[7] B. Chen and J. Liu, "Contribution of hybrid fibers on the properties of the high-strength lightweight concrete having good workability," Cement and Concrete Research, vol. 35, no. 5, pp. 913-917, 2005.

[8] P. Shafigh, H. Mahmud, and M. Z. Jumaat, "Effect of steel fiber on the mechanical properties of oil palm shell lightweight concrete," Materials and Design, vol. 32, no. 7, pp. 3926-3932, 2011.

[9] S. P. Yap, U. J. Alengaram, and M. Z. Jumaat, "Enhancement of mechanical properties in polypropylene- and nylon-fibre reinforced oil palm shell concrete," Materials \& Design, vol. 49, pp. 1034-1041, 2013.

[10] R. Polat, R. Demirboğa, M. B. Karakoç, and I. Türkmen, "The influence of lightweight aggregate on the physico-mechanical properties of concrete exposed to freeze-thaw cycles," Cold Regions Science and Technology, vol. 60, no. 1, pp. 51-56, 2010.

[11] A. M. Neville and J. J. Brooks, Concrete Technology, Pearson Education Asia Pte, Kuala Lumpur, Malaysia, 2008.

[12] V. Subramaniam, A. N. Ma, Y. M. Choo, and N. M. N. Sulaiman, "Environmental performance of the milling process of Malaysian palm oil using the life cycle assessment approach," American Journal of Environmental Sciences, vol. 4, no. 4, pp. 310-315, 2008.

[13] D. C. L. Teo, M. A. Mannan, and J. V. Kurian, "Flexural behaviour of reinforced lightweight concrete beams made with oil palm shell (OPS)," Journal of Advanced Concrete Technology, vol. 4, no. 3, pp. 459-468, 2006.

[14] D. C. Okpala, "Palm kernel shell as a lightweight aggregate in concrete," Building and Environment, vol. 25, no. 4, pp. 291-296, 1990.
[15] F. O. Okafor, "Palm kernel shell as a lightweight aggregate for concrete," Cement and Concrete Research, vol. 18, no. 6, pp. 901910, 1988.

[16] P. Shafigh, M. Z. Jumaat, and H. Mahmud, "Oil palm shell as a lightweight aggregate for production high strength lightweight concrete," Construction and Building Materials, vol. 25, no. 4, pp. 1848-1853, 2011.

[17] J. Newman and P. Owens, Properties of Lightweight Concrete, Advanced Concrete Technology Set, Butterworth-Heinemann, Oxford, UK, 2003.

[18] Z. Li, Advanced Concrete Technology, John Wiley \& Sons, 2011.

[19] ASTM C192-90a, "Standard test method of making and curing concrete test specimens in the laboratory," in Annual Book of ASTM Standards, 1990.

[20] M. K. Yew, H. B. Mahmud, B. C. Ang, and M. C. Yew, "Effects of heat treatment on oil palm shell coarse aggregates for high strength lightweight concrete," Materials and Design, vol. 54, pp. 702-707, 2014.

[21] M. K. Yew, I. Othman, M. C. Yew, S. H. Yeo, and H. B. Mahmud, "Strength properties of hybrid nylon-steel and polypropylenesteel fibre-reinforced high strength concrete at low volume fraction," International Journal of Physical Sciences, vol. 6, no. 33, pp. 7584-7588, 2011.

[22] N. A. Memon, S. R. Sumadi, and M. Ramli, "Performance of high wokability slag-cement mortar for ferrocement," Building and Environment, vol. 42, no. 7, pp. 2710-2717, 2007.

[23] A. Noushini, K. Vessalas, G. Arabian, and B. Samali, "Drying shrinkage behaviour of fiber reinforced concrete incorporating polyvinyl alcohol fibers and fly ash," Advances in Civil Engineering, vol. 2014, Article ID 836173, 10 pages, 2014.

[24] C. Qian and P. Stroeven, "Fracture properties of concrete reinforced with steel-polypropylene hybrid fibres," Cement and Concrete Composites, vol. 22, no. 5, pp. 343-351, 2000.

[25] E. T. Dawood and M. Ramli, "Flowable high-strength system as repair material," Structural Concrete, vol. 11, no. 4, pp. 199-209, 2010.

[26] G. Lu, K. Wang, and T. J. Rudolphi, "Modeling rheological behavior of highly flowable mortar using concepts of particle and fluid mechanics," Cement and Concrete Composites, vol. 30, no. 1, pp. 1-12, 2008.

[27] H. Okamura and M. Ouchi, "Self compacting concrete," Journal of Advanced Concrete Technology, vol. 1, pp. 5-15, 2003.

[28] M. K. Yew and I. Othman, "Mechanical properties of hybrid nylon-steel- and steel-fibre-reinforced high strength concrete at low fibre volume fraction," Advanced Materials Research, vol. 168-170, pp. 1704-1707, 2011.

[29] G. Campione, N. Miraglia, and M. Papia, "Mechanical properties of steel fibre reinforced lightweight concrete with pumice stone or expanded clay aggregates," Materials and Structures, vol. 34, no. 238, pp. 201-210, 2001.

[30] A. Sivakumar, "Influence of hybrid fibers on the post crack performance of high strength concrete: part I experimental investigations," Journal of Civil Engineering Construction Technology, vol. 2, no. 7, pp. 147-159, 2011.

[31] L. Domagala, "Modification of properties of structural lightweight concrete with steel fibres," Journal of Civil Engineering and Management, vol. 17, no. 1, pp. 36-44, 2011.

[32] B. Arisoy and H.-C. Wu, "Material characteristics of high performance lightweight concrete reinforced with PVA," Construction and Building Materials, vol. 22, no. 4, pp. 635-645, 2008. 
[33] M. K. Yew, H. Mahmud, B. C. Ang, and M. C. Yew, "Enhancement of mechanical properties in polypropylene twisted bundle fiber-reinforced oil palm shell high-strength lightweight concrete," in Proceedings of the 8th International Conference on Engineering and Technology Research, Novotel World Trade Centre, Dubai, UAE, 2014.

[34] M. A. Mannan, J. Alexander, C. Ganapathy, and D. C. L. Teo, "Quality improvement of oil palm shell (OPS) as coarse aggregate in lightweight concrete," Building and Environment, vol. 41, no. 9, pp. 1239-1242, 2006.

[35] U. J. Alengaram, H. Mahmud, and M. Z. Jumaat, "Enhancement and prediction of modulus of elasticity of palm kernel shell concrete," Materials and Design, vol. 32, no. 4, pp. 2143-2148, 2011.

[36] J. Newman and B. S. Choo, Advanced Concrete Technology: Testing and Quality, Butterworth-Heinemann, Oxford, UK, 2003.

[37] S. Chandra and L. Berntsson, Lightweight Aggregate Concrete: Science, Technology, and Applications, Noyes/William A, New York, NY, USA, 2002.

[38] I. B. Topçu and T. Uygunoğlu, "Effect of aggregate type on properties of hardened self-consolidating lightweight concrete (SCLC)," Construction and Building Materials, vol. 24, no. 7, pp. 1286-1295, 2010.

[39] R. V. Balendran, F. P. Zhou, A. Nadeem, and A. Y. T. Leung, "Influence of steel fibres on strength and ductility of normal and lightweight high strength concrete," Building and Environment, vol. 37, no. 12, pp. 1361-1367, 2002.

[40] P. Shafigh, H. B. Mahmud, and M. Z. Jumaat, "Oil palm shell lightweight concrete as a ductile material," Materials and Design, vol. 36, pp. 650-654, 2012.

[41] A. Turatsinze and M. Garros, "On the modulus of elasticity and strain capacity of self-compacting concrete incorporating rubber aggregates," Resources, Conservation and Recycling, vol. 52, no. 10, pp. 1209-1215, 2008.

[42] H. Akbar, Design of Reinforced Concrete Structures, vol. 1, Basic topics, Simay Danesh, Tehran, Iran, 2008.

[43] Z. Li, Advanced Concrete Technology, John Wiley \& Sons, New York, NY, USA, 2011.

[44] P. Balaguru and A. Foden, "Properties of fiber reinforced structural lightweight concrete," ACI Structural Journal, vol. 93, no. 1, pp. 62-78, 1996.

[45] P. Balaguru and M. G. Dipsia, "Properties of fiber reinforced high-strength semilightweight concrete," ACI Materials Journal, vol. 90 , no. 5, pp. 399-405, 1993.

[46] U. J. Alengaram, M. Z. Jumaat, and H. Mahmud, "Influence of sand content and silica fume on mechanical properties of palm kernel shell concrete," in Proceedings of the International Conference on Construction and Building Technology (ICCBT '08), pp. 251-262, 2008.

[47] M. A. Mannan and C. Ganapathy, "Engineering properties of concrete with oil palm shell as coarse aggregate," Construction and Building Materials, vol. 16, no. 1, pp. 29-34, 2002.

[48] U. J. Alengaram, M. Z. Jumaat, and H. Mahmud, "Ductility behaviour of reinforced palm kernel shell concrete beams," European Journal of Scientific Research, vol. 23, no. 3, pp. 406420, 2008.

[49] T. Y. Lo, H. Z. Cui, and Z. G. Li, "Influence of aggregate prewetting and fly ash on mechanical properties of lightweight concrete," Waste Management, vol. 24, no. 4, pp. 333-338, 2004.
[50] C. Shi, Y. Wu, and M. Riefler, "Properties of fiber-reinforced lightweight concrete," ACI Special Publication, vol. 226, pp. 123134, 2005.

[51] CEB/FIP Manual of Design and Technology, Lightweight Aggregate Concrete, 1997.

[52] R. N. Swamy and G. H. Lambert, "Mix design and properties of concrete made from PFA coarse aggregates and sand," International Journal of Cement Composites and Lightweight Concrete, vol. 5, no. 4, pp. 263-275, 1983.

[53] P. K. Mehta and P. J. M. Monteiro, Concrete: Microstructure, Properties, and Materials, McGraw-Hill, New York, NY, USA, 3rd edition, 2006.

[54] H. Mazaheripour, S. Ghanbarpour, S. H. Mirmoradi, and I. Hosseinpour, "The effect of polypropylene fibers on the properties of fresh and hardened lightweight self-compacting concrete," Construction and Building Materials, vol. 25, no. 1, pp. 351-358, 2011. 

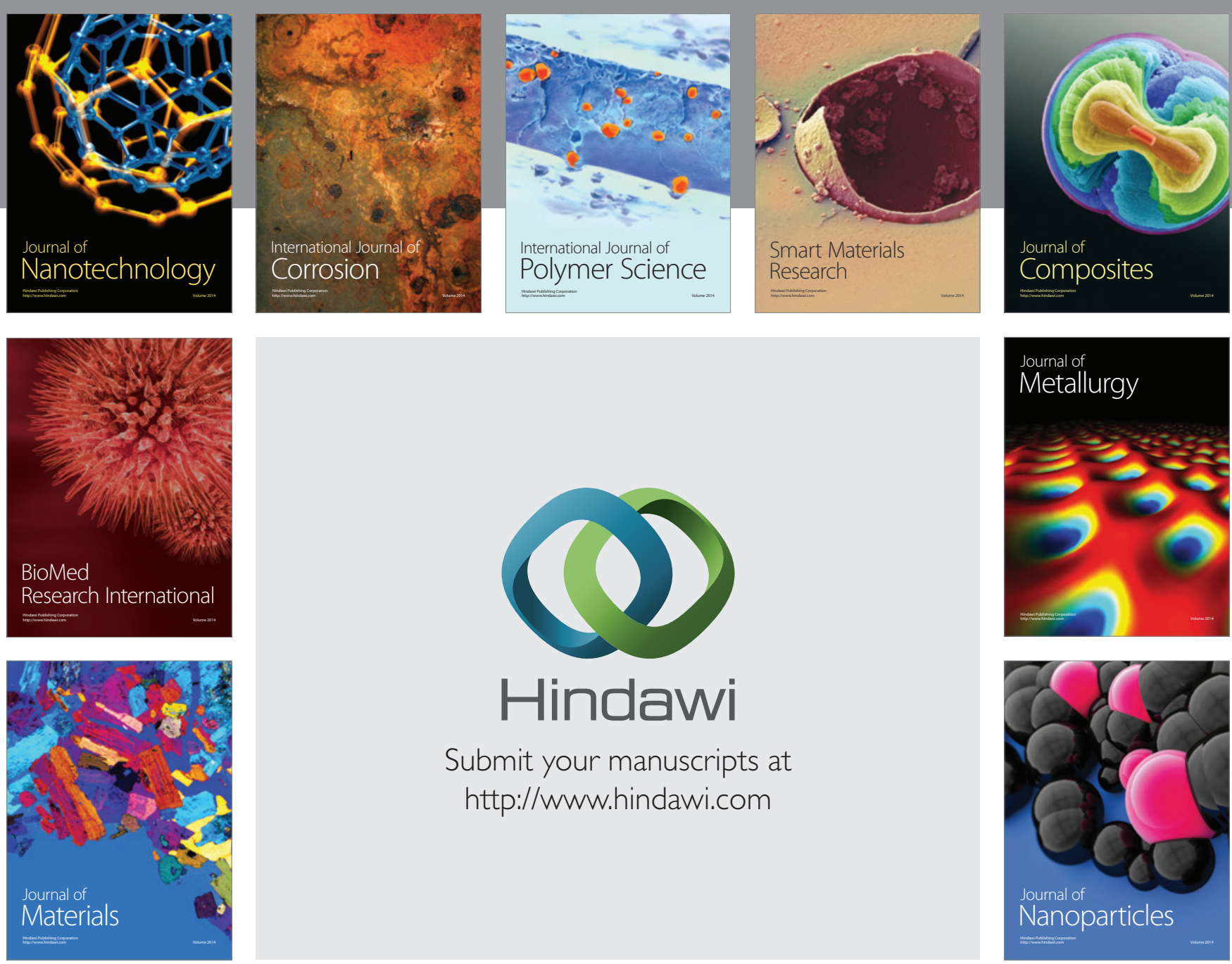

Submit your manuscripts at http://www.hindawi.com
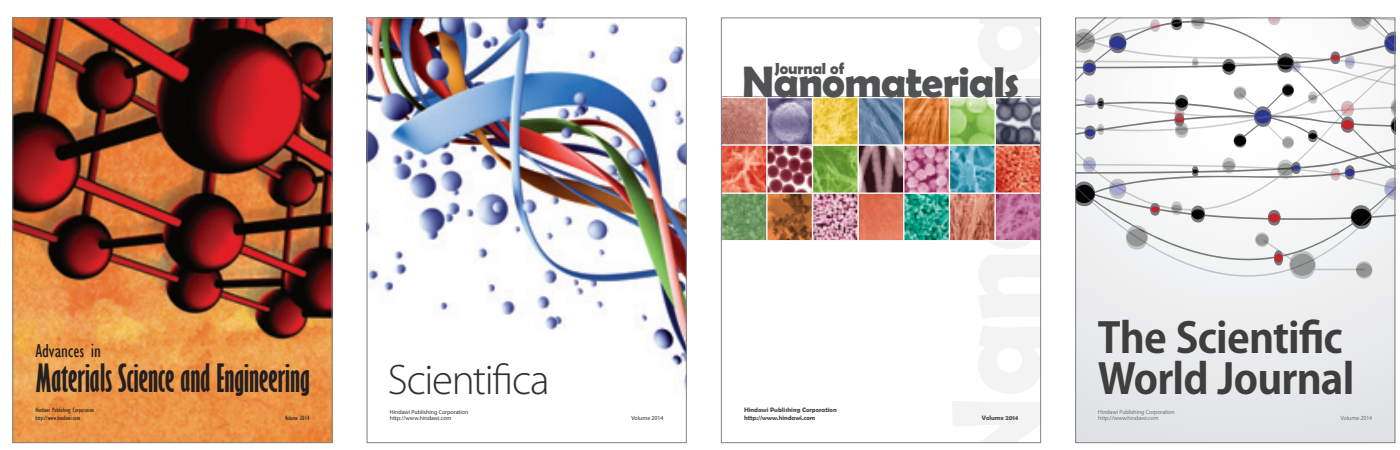

\section{The Scientific World Journal}
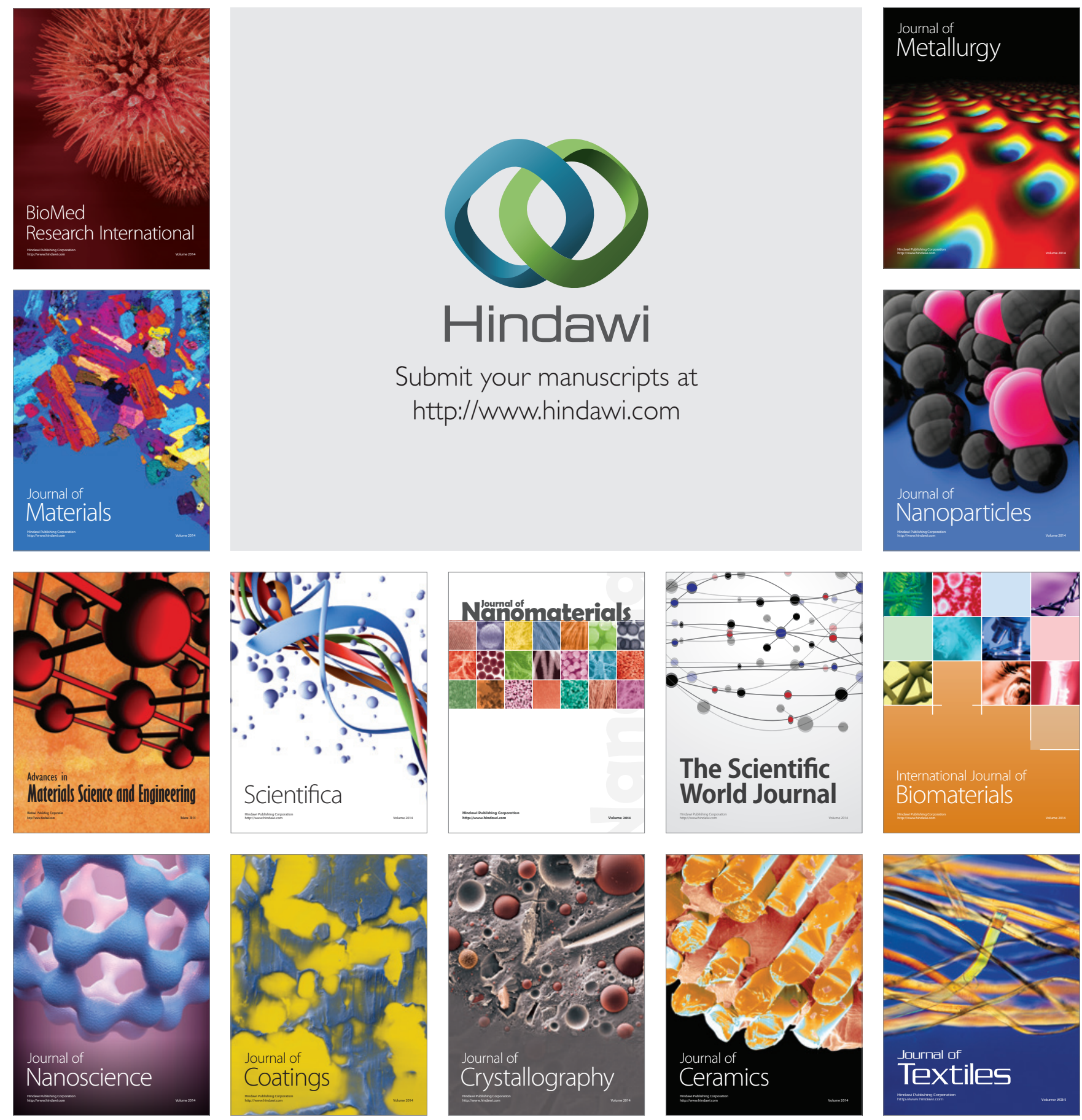